\title{
BMJ Open Educational disparities in the intention to quit smoking among male smokers in China: a cross-sectional survey on the explanations provided by the theory of planned behaviour
}

\author{
Mariël Droomers, ${ }^{1}$ Xinyuan Huang, ${ }^{1}$ Wenjie Fu, ${ }^{1,2}$ Yong Yang, ${ }^{3}$ Hong Li, ${ }^{4}$ \\ Pinpin Zheng ${ }^{1}$
}

To cite: Droomers $M$, Huang X, Fu W, et al. Educational disparities in the intention to quit smoking among male smokers in China: a cross-sectional survey on the explanations provided by the theory of planned behaviour. BMJ Open 2016;6:e011058. doi:10.1136/bmjopen-2016011058

- Prepublication history for this paper is available online. To view these files please visit the journal online (http://dx.doi.org/10.1136/ bmjopen-2016-011058).

$\mathrm{XH}$ joint first author.

Received 9 January 2016 Revised 30 August 2016 Accepted 7 September 2016

CrossMark

For numbered affiliations see end of article.

Correspondence to Dr Pinpin Zheng; zpinpin@ shmu.edu.cn

\section{ABSTRACT}

Objectives: We aim to describe the intention to quit smoking among Chinese male smokers from different educational backgrounds and to explain this intention from their attitude, perceived social norms and selfefficacy regarding smoking cessation.

Setting: Participants were recruited from workplaces and communities to reflect the occupational distribution in three cities (Shanghai, Nanning and Mudanjiang) in China.

Design and participants: In 2013 interviews were conducted with 3676 male smokers aged 18 years and older.

Outcome measures: Multivariate logistic regression analyses calculated educational differences in the intention to quit smoking as well as the association between the intention to quit smoking and attitude, subjective norms, and self-efficacy. Bootstrapping estimated to what extent the educational disparities in the intention to quit smoking were mediated by these three determinants.

Results: No educational disparities in the intention to quit smoking within 1 or 6 months were observed among male Chinese smokers ( $p=0.623$ and $p=0.153$, respectively). A less negative attitude, a higher perceived subjective norm towards smoking cessation, and a higher perceived self-efficacy to quit smoking were all associated with intention to quit (all $p$ values $<0.001$ ). Perceived subjective norms were the only component of the theory of planned behaviour that statistically significantly mediated the differences in the intention to quit smoking (within 1 or 6 months) between the lowest educated Chinese men and the groups with lower $(\beta=0.039,95 \% \mathrm{Cl} 0.017$ to 0.071 and $\beta=0.043,95 \% \mathrm{Cl}$ 0.019 to 0.073$)$, higher $(\beta=0.041,95 \% \mathrm{Cl} 0.017$ to 0.075 and $\beta=0.045,95 \% \mathrm{Cl} 0.019$ to 0.077 ) and the highest education ( $\beta=0.045,95 \% \mathrm{Cl} 0.019$ to 0.080 and $\beta=0.050,95 \% \mathrm{Cl} 0.023$ to 0.083 ).

Conclusions: In order to prevent future socioeconomic disparities in smoking cessation, investment in a more stimulating social environment and norms towards smoking cessation among particularly the lowest educated Chinese men is warranted.
Strengths and limitations of this study

- This is the first survey that interviewed a large number of Chinese males about their beliefs regarding smoking cessation.

- All the beliefs and attitudes questioned were derived from extensive qualitative research among Chinese male smokers from diverse socioeconomic backgrounds, and were therefore highly culturally relevant.

- This procedure, however, yielded only beliefs regarding consequences of quitting smoking for the respondent's own health, but not for the health of others, and included only negative consequences, but no positive ones. Furthermore, the attitude was based on evaluative judgements only and did not include affective judgements concerning the positive or negative feelings derived from the behaviour.

- As we interviewed Chinese male smokers only, we cannot draw any conclusions on socioeconomic disparities regarding smoking and smoking cessation among Chinese women, who, on the contrary, rarely smoke (smoking prevalence $<3 \%$ ).

- We used a composite measure for subjective norms, which included the perceived norms, as well as the motivation to comply to the norms. The latter however may add little predictive power; in fact it tends to suppress the correlations. Nevertheless, when we omitted motivation to comply from the analyses and only analysed normative beliefs, we reached the same conclusions as presented in this paper.

\section{INTRODUCTION}

Smoking rates are usually higher among lower socioeconomic groups than among their peers with a higher socioeconomic status. These socioeconomic disparities in smoking are one of the most important reasons for existing socioeconomic disparities 
in health and mortality. ${ }^{1-3}$ If inequalities in smoking could be eliminated in Europe, the potential reduction in relative inequality in all-cause mortality between those with high and low education amounts up to $26 \%$ for men and $32 \%$ for women. ${ }^{1}$ For some causes of death, even more than half of the relative inequalities may be reduced in Northern European countries and Britain. ${ }^{1}$ Calculations based on data from England, Wales, Poland, USA and Canada revealed that smoking-attributed mortality accounted for more than half (range from $51 \%$ in Canada to $65 \%$ in Poland) of the absolute difference between the highest and lowest social strata in total male mortality rates at ages 3569 years. $^{3}$

Socioeconomic disparities in smoking behaviour also occur in China. The Global Adult Tobacco Survey reported higher smoking rates among the less-educated men aged 15 years and older in China during 20082010 than among higher educated men. The smoking prevalence among men with high school education or lower was between $58.2 \%$ and $63.2 \%$, while among men who finished college or a higher educational level the smoking rate was $44 \% .{ }^{4}$ Likewise, the World Health Survey, carried out in 2003, revealed that the prevalence of smoking in China rises when the level of wealth decreases. ${ }^{5}$ In China, the smoking rate among men is much higher than among women $(52.8 \%$ vs $2.4 \%){ }^{6}$ China is among those countries with the highest smoking prevalence among men and the lowest among women. $^{7}$ Furthermore, the quit ratio between 2006 and 2012 in China was low compared to other countries. ${ }^{7}$ The corresponding need for effective interventions to help smokers quit would benefit tremendously from more knowledge about the determinants of the smoking cessation among Chinese smokers.

Socioeconomic differences in smoking behaviour among adults not only result from socioeconomic differences in the initiation of daily smoking during adolescence or early adulthood, ${ }^{9-11}$ it also results from adults with a lower socioeconomic status being less successful at quitting than higher socioeconomic groups. ${ }^{11-14}$

In order to quit smoking successfully, the theory of planned behaviour (TPB) ${ }^{15}$ states that a smoker first needs to have the intention to quit and has to believe in his or her own ability to succeed, that is, self-efficacy. Intentions translate into behaviour to the extent that the person has adequate self-efficacy or behavioural control, and behavioural control influences behaviour to the extent that the person is motivated to try. ${ }^{15}$ The intention to quit smoking is in turn shaped by the smoker's personal attitude towards smoking cessation, the perceived subjective or social norms regarding smoking cessation and by the perceived self-efficacy or the trust in one's own ability to actually quit smoking (figure 1). As a rule, the more favourable the attitude and subjective norms, and the greater perceived behavioural control, the stronger an individual's intention is to perform the behaviour under consideration. ${ }^{15}$
Although the TPB is often criticised for being too rational and excluding unintentional influences on behaviour $^{16}$ and the role of emotions beyond anticipated affective outcomes, ${ }^{17}{ }^{18}$ its application provides a host of information to inform the development of effective health promotion interventions. For example, when the TPB was used to explain educational differences in the intention to quit smoking in the Netherlands, ${ }^{12}$ it was concluded that in the Dutch context only the direct effect of self-efficacy on behaviour contributed to the educational differences in smoking cessation. Hence self-efficacy should be the focus of interventions aiming to reduce educational inequalities in smoking.

In this paper we investigate how the elements of the TPB might explain educational disparities in the intention to quit smoking in a Chinese context. We developed culturally appropriate measures of the different components of the TPB. We describe the intention to quit smoking among Chinese men with different educational backgrounds. Furthermore, we try to explain the intention to quit smoking from: (1) the attitude towards smoking cessation, (2) the perceived social norms and (3) self-efficacy regarding smoking cessation. Last, we analysed whether these variables mediate educational disparities in intention to quit among Chinese male smokers.

\section{METHODS}

\section{Study population}

We conducted a cross-sectional survey on smoking beliefs among male smokers living in three cities (Shanghai, Nanning and Mudanjiang) in China between September and December 2013. Shanghai, located in Eastern China, has a relatively low smoking rate. It was the first city to implement smoke-free legislation, and is one of the most economically developed cities in China. Nanning, located in the Southwest of the country, is a second-tier city in China. At the time of our survey, no legislation for smoke-free public places was in place in Nanning; however, a plan has been developed since then. Mudanjiang, located in the Northeast of China and a third-tier city, has a relatively high smoking rate and lags behind in tobacco control legislation.

Men aged 18 years or older, having smoked at least 100 cigarettes or at least smoked one cigarette in the past month, were eligible for the study. The study focused on men, because in China the smoking rate among men is much higher than among women (52.8\% vs $2.4 \%$ ) who comprise only $4.8 \%$ of the total Chinese smokers. ${ }^{6}$

Participants were recruited using two different sampling procedures, that is, one in local workplaces to recruit working men and one in certain residential communities to recruit retirees. In collaboration with the local Centers for Disease Control and Prevention (CDC), we selected workplaces that represented the main occupational categories in the Chinese Population 
Figure 1 The theory of planned behaviour applied to educational differences in the intention to quit smoking (and smoking cessation).

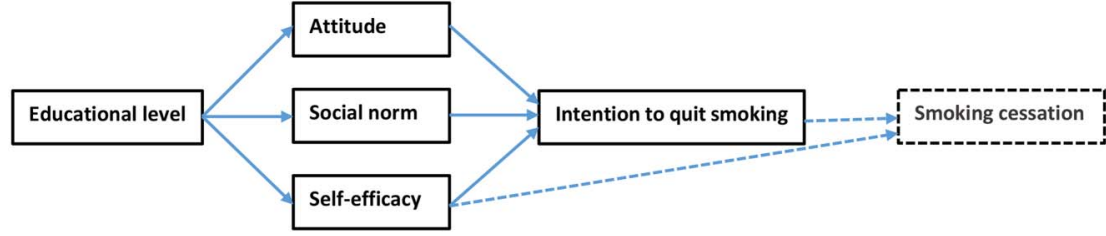

and Employment Statistical Yearbook of 2013 (including government and corporate officers, professional employees, business men, hospitality workers, farmers and manual workers). ${ }^{19}$ If a workplace agreed to participate, all smokers' names were listed and numbered, the researchers then selected the required number of participants randomly. The number of participants in that particular occupational category reflected the distribution of occupational status in the city surveyed (probability-proportional-to-size sampling). We supplemented workplace-based sampling with a community sample of retirees. We randomly selected one rural and one urban community within each of the three cities. Likewise, retired male smokers were recruited with the help of the local CDC. The number of retired respondents invited in each community reflected the distribution of retirees in rural and urban areas in that particular city. This two-tiered sampling strategy was developed, because community-based sampling alone would have oversampled retirees who are less likely to be current smokers.

With the help of local CDC and the managers of the workplaces/communities, smokers provided informed consent and agreed to participate. The overall consent rate was $96.5 \%$. An anonymous self-reported questionnaire was administered and trained research assistants were present for quality control and in case of questions. The survey yielded 3780 respondents.

\section{Smoking behaviour}

Smokers were defined as those answering yes to the question 'Have you smoked at least 100 cigarettes in your entire life?' Daily smokers were those who stated that they smoked one cigarette or more when answering the question 'On average, on the days you smoke, how many cigarettes do you smoke in a day?'
Intention to quit smoking

The TPB states that for an accurate prediction of intention, the measures of intention must correspond to and be compatible with the particular behaviour that is to be predicted. ${ }^{11}$ We measured the intention to quit smoking in the next 6 months as well as the next month using the question 'Which of the following best describes your intention to quit?' with four response categories (1) never expect to quit, (2) may quit in the future, but not in the next 6 months, (3) will quit in the next 6 months, (4) will quit in the next month.

\section{Attitude towards smoking cessation}

The attitude towards a behaviour refers to the degree to which a person has a favourable or unfavourable evaluation or appraisal of the behaviour in question. ${ }^{15}$ Attitude figure was calculated by summing the answers to three different statements on evaluative beliefs about the impact of quitting smoking, and subsequently dividing this sum score into tertiles. These beliefs were derived from extensive qualitative research among Chinese male smokers from diverse socioeconomic backgrounds, and were therefore highly culturally relevant. ${ }^{20}$ Beliefs included weight gain, fear to relapse and smoke even more and loss of body balance, the latter being an important belief rooted in traditional Chinese medicine. Response categories ranged from strongly agree to strongly disagree on a five-point Likert scale (table 1).

\section{Subjective norms}

The subjective norms refer to the perceived social pressure performing or not performing the behaviour. The measure of subjective norms includes normative beliefs about how smoking cessation is valued by others combined with the respondents' motivation to comply with the opinion of each of these people ${ }^{15}$ We calculated the

Table 1 Construct information on the components of the theory of planned behaviour

\begin{tabular}{|c|c|c|c|c|c|c|}
\hline Construct & $\begin{array}{l}\text { Number } \\
\text { of items }\end{array}$ & Range & $\mathbf{N}$ & Mean/SD & Cronbach's $\alpha$ & $\begin{array}{l}\text { Cumulative variance } \\
\text { contribution }(\%)^{\star}\end{array}$ \\
\hline $\begin{array}{l}\text { Attitude towards smoking } \\
\text { cessation }\end{array}$ & 3 & $3-15$ & 3674 & $8.45 / 2.33$ & 0.739 & 65.67 \\
\hline Subjective norm & $\mathrm{NB} \times \mathrm{MC}$ & $4-80$ & 3664 & $27.63 / 12.36$ & 0.706 & - \\
\hline Normative beliefs (NB) & 4 & $4-21$ & 3670 & $11.39 / 3.18$ & 0.794 & 63.50 \\
\hline Motivation to comply (MC) & 1 & $1-4$ & 3670 & $2.60 / 0.75$ & - & - \\
\hline Self-efficacy & 1 & $1-5$ & 3675 & 2.86/3.18 & - & - \\
\hline
\end{tabular}


Table 2 Descriptive demographics of the study population $(\mathrm{N}=3676)$ by city

\begin{tabular}{lllll}
\hline Demographics & Shanghai & Nanning & \multicolumn{1}{l}{ Mudanjiang } & \multicolumn{1}{l}{ Total } \\
\hline Age (mean/SD) & $41.34 / 14.58$ & $40.21 / 15.03$ & $40.43 / 13.46$ & $40.69 / 14.39$ \\
Educational level (\% (no)) & & & & \\
$\quad$ Lowest & $29.6(391)$ & $35.9(423)$ & $24.4(287)$ & $30.0(1101)$ \\
$\quad$ Lower & $28.1(371)$ & $22.8(269)$ & $30.7(361)$ & $27.3(1001)$ \\
$\quad$ Higher & $17.5(231)$ & $21.2(250)$ & $21.4(251)$ & $19.9(732)$ \\
$\quad$ Highest & $24.8(327)$ & $20.1(237)$ & $23.4(275)$ & $22.8(839)$ \\
Marital status (\% (no)) & & & & \\
$\quad$ Married & $79.6(1045)$ & $70.1(828)$ & $70.1(822)$ & $73.5(2695)$ \\
$\quad$ Not married & $20.4(267)$ & $29.9(353)$ & $29.9(350)$ & $26.5(970)$ \\
Smoking pattern (\% (no)) & $99.5(1313)$ & $100.0(1181)$ & $100.0(1174)$ & $99.8(3668)$ \\
$\quad$ Daily smokers & & & \\
$\quad$ Intention to quit (\% (no)) & & & $13.4(157)$ & $11.1(406)$ \\
$\quad$ Within 1 month & $8.4(111)$ & $11.7(138)$ & $24.5(288)$ & $19.9(730)$ \\
$\quad$ Within 6 months & $16.5(217)$ & & & \\
\hline
\end{tabular}

subjective norms by multiplying the sum score of normative beliefs of each individual by their motivation to comply, and categorised this continuous variable into tertiles. The score on normative beliefs summed the answers to four questions regarding the perceived pressure to quit smoking from family member, people close to the respondent (relatives, colleagues and friends) and others. Response options to the three questions 'How often are you criticised for smoking by others?', 'Do your family members often urge you to quit smoking?', and 'Do people around you (relatives, colleagues, friends) often urge you to quit smoking?' ranged from 'never' to 'very often' on a five-point Likert scale. The fourth question was 'Thinking about the people around you: How many of them think that you should quit smoking?' with the response categories: (1) none, (2) a few, (3) less than half, (4) about half, (5) most and (6) all. We derived the motivation to comply to the beliefs of others from the question asking 'In general, how much do you care about the opinion of people around you?' Response categories were (1) not at all, (2) not that much, (3) somewhat and (4) (very) much.

\section{Self-efficacy}

Self-efficacy regarding smoking cessation was measured using the question 'If you decide to quit smoking in the next six months, how confident are you that you could quit smoking?' Possible answers were (1) not at all sure,
(2) not very sure, (3) more or less sure, (4) fairly sure and (5) absolutely sure.

\section{Educational level}

The highest educational attainment was categorised into four groups, that is, (1) less than primary school to junior high school, (2) high school or technical (secondary) school, (3) junior college and (4) college graduate or higher.

\section{Analyses}

Analyses were performed using complete cases only $(\mathrm{n}=3676,97.2 \%)$, excluding respondents younger than 18 years, who have smoked $<100$ cigarettes, or with missing or incomplete answers $(\mathrm{n}=104,2.8 \%)$. Crosstabs and $\chi^{2}$ tests were conducted to assess univariate associations between educational level, elements of the TPB and the intention to quit. Multilevel logistic regression analyses with individual smokers on level 1 and cities on level 2, were executed using MLwiN V.2.36, suggested that there was no statistically significant difference between cities in the intention to quit smoking with 1 month $(p=0.319)$ and 6 months $(p=0.281)$. The intraclass correlation or the variance in the intention to quit that was attributable to the city level was estimated to amount $1.1 \%$ only. We therefore fitted general multivariate regression models, to calculate the difference in the intention to quit smoking and the elements of the TPB between different educational groups,

Table 3 Association between educational level and intention to quit smoking among smokers ( $N=3676$ )

\begin{tabular}{|c|c|c|c|c|}
\hline \multirow[b]{2}{*}{ Educational level } & \multicolumn{2}{|c|}{$\begin{array}{l}\text { Intention to quit smoking within } \\
1 \text { month }\end{array}$} & \multicolumn{2}{|c|}{$\begin{array}{l}\text { Intention to quit smoking within } \\
6 \text { months }\end{array}$} \\
\hline & Per cent & OR $(95 \% \mathrm{Cl})^{\star}$ & Per cent & OR $(95 \% \mathrm{Cl})^{*}$ \\
\hline Lowest & 10.2 & 1.00 & 18.3 & 1.00 \\
\hline Lower & 10.5 & $0.85(0.64$ to 1.14$)$ & 19.8 & $0.92(0.73$ to 1.16$)$ \\
\hline Higher & 12.5 & $0.98(0.72$ to 1.33$)$ & 23.0 & 1.07 (0.84 to 1.36$)$ \\
\hline Highest & 11.7 & $0.86(0.63$ to 1.17$)$ & 19.5 & 0.81 (0.96 to 1.46$)$ \\
\hline
\end{tabular}


Table 4 Association between elements of theory of planned behaviour and intention to quit ( $N=3676)$

\begin{tabular}{|c|c|c|c|c|}
\hline \multirow[b]{2}{*}{ Elements of theory of planned behaviour } & \multicolumn{2}{|c|}{$\begin{array}{l}\text { Intention to quit smoking within } \\
1 \text { month }\end{array}$} & \multicolumn{2}{|c|}{$\begin{array}{l}\text { Intention to quit smoking within } \\
6 \text { months }\end{array}$} \\
\hline & OR $(95 \% \mathrm{Cl})^{*}$ & p Value & OR $(95 \% \mathrm{Cl})^{\star}$ & p Value \\
\hline Attitude towards smoking cessation & & $<0.001$ & & $<0.001$ \\
\hline Most negative (highest score) & 1.00 & & 1.00 & \\
\hline Intermediate & 1.49 (1.13 to 1.98$)$ & & $1.60(1.29$ to 1.98$)$ & \\
\hline Least negative (lowest score) & 2.21 (1.68 to 2.91$)$ & & 2.03 (1.64 to 2.52$)$ & \\
\hline Subjective norms & & $<0.001$ & & $<0.001$ \\
\hline Lowest norm (lowest score) & 1.00 & & 1.00 & \\
\hline Intermediate & 1.59 (1.19 to 2.13$)$ & & 1.89 (1.50 to 2.37$)$ & \\
\hline Highest norm (highest score) & 2.19 (1.64 to 2.91$)$ & & 2.48 (1.98 to 3.11$)$ & \\
\hline Self-efficacy & & $<0.001$ & & $<0.001$ \\
\hline Not at all sure & 1.00 & & 1.00 & \\
\hline Not very sure & 3.46 (1.81 to 6.61$)$ & & $3.74(2.30$ to 6.09$)$ & \\
\hline More or less sure & 4.54 (2.42 to 8.52$)$ & & 4.95 (3.08 to 7.95$)$ & \\
\hline Fairly sure & 8.13 (4.29 to 15.42$)$ & & 12.16 (7.51 to 19.69$)$ & \\
\hline Absolutely sure & 12.84 (6.70 to 24.62$)$ & & 11.65 (7.05 to 19.22$)$ & \\
\hline
\end{tabular}

adjusted for age, marital status (married vs not married), the number of cigarettes smoked per day and city. The highest level of educational attainment served as the reference category in all the analyses on educational differences.

We used a bootstrapping method $(n=5000)$ to perform mediation analyses to estimate the contribution of the elements of the TPB to the educational differences in the intention to quit smoking. ${ }^{21}$ Bootstrapping allows for the calculation of CIs around the estimated direct and indirect effects. We used the PROCESS macro (downloaded from http://www.afhayes.com/) to perform mediation analyses with the intention to quit smoking as the outcome variable, the educational level as the independent variable and the elements of the TPB as mediators, adjusted for age, marital status, the number of cigarettes smoked per day and city. SPSS (IBM SPSS Statistics V.19.0) was used for all statistical analyses.

\section{RESULTS}

The male participants were on average a slightly over 40 years, while one-quarter was not married. Male smokers living in Shanghai were on average a little older and more likely to be single, while men living in Nanning were less educated than the participants from other cities. Most $(99.8 \%)$ of the participants were daily smokers (table 2).

Table 2 shows that $11.1 \%$ of the male Chinese smokers said that they intended to quit smoking within 1 month. Almost twice as many $(19.9 \%)$ intended to quit within the coming 6 months. The lowest educated group reported the lowest prevalence of intention to quit, but the highest educated men did not report the highest prevalence. In other words, there was no educational gradient in the intention to quit smoking. There were also no statistically significant educational disparities in

\begin{tabular}{|c|c|c|c|c|c|}
\hline \multirow[b]{2}{*}{ Elements of theory of planned behaviour } & \multicolumn{4}{|c|}{ Educational level (\%) } & \multirow[b]{2}{*}{ p Value } \\
\hline & Lowest & Lower & Higher & Highest & \\
\hline Attitude towards smoking cessation & & & & & $<0.001$ \\
\hline Most negative (highest score) & 36.6 & 33.3 & 35.2 & 31.5 & \\
\hline Intermediate & 38.4 & 35.6 & 31.3 & 34.7 & \\
\hline Least negative (lowest score) & 25.0 & 31.3 & 33.5 & 33.8 & \\
\hline Subjective norms & & & & & $<0.001$ \\
\hline Lowest norm (lowest score) & 39.7 & 26.9 & 28.5 & 26.8 & \\
\hline Intermediate & 33.1 & 37.8 & 36.2 & 37.1 & \\
\hline Highest norm (highest score) & 27.2 & 35.3 & 35.3 & 36.1 & \\
\hline Self-efficacy & & & & & $<0.001$ \\
\hline Not at all sure & 17.1 & 12.6 & 14.8 & 9.9 & \\
\hline Not very sure & 25.6 & 24.1 & 25.9 & 22.9 & \\
\hline More or less sure & 34.4 & 36.6 & 30.6 & 33.4 & \\
\hline Fairly sure & 13.9 & 18.6 & 17.1 & 16.9 & \\
\hline Absolutely sure & 8.4 & 8.2 & 11.6 & 16.9 & \\
\hline
\end{tabular}


the intention to quit smoking, neither within 1 month ( $\mathrm{p}=0.623$ ) nor within 6 months $(\mathrm{p}=0.153)$ (table 3$)$.

All elements of the TPB were statistically significantly associated with the intention to quit smoking, either within 1 or 6 months (table 4). The less negative the attitude towards smoking cessation, the stronger the perceived subjective norms towards smoking cessation and the more sure they are about their own ability to succeed, the higher are the odds that the smoker intended to quit smoking within 1 or 6 months (table 4).

Most of the characteristics that were positively associated with the intention to quit smoking were more often reported by those with a higher educational level. For example, the higher the educational level, the higher the prevalence of the least negative attitude towards smoking cessation and the stronger the perceived social norms favouring smoking cessation (table 5). The educational pattern regarding self-efficacy was less clear, though the two highest educated groups reported the highest prevalence of self-efficacy (table 5).

Even though no educational disparities in the intention to quit smoking were observed initially, we preformed mediation analyses, as recommended by Hayes. ${ }^{21}$ The lack of an association between educational level and the intention to quit smoking might have resulted from one (group of) mediator(s) causing lower educational groups to more often report the intention to quit and another (group of) mediator(s) causing lower educational groups to less often intend to quit smoking. Therefore, even in the absence of educational differences in the intention to quit smoking, variables that are related to the intention and educational level could still potentially mediate educational disparities in the intention to quit smoking. ${ }^{21}$ Our mediation analyses showed that indeed the lack of observable educational differences in the intention to quit smoking resulted from a positive association between educational level and cessation intention via the components of the TPB that was cancelled out by an inverse direct association between educational level and the intention to quit smoking within 1 and 6 months (table 6). The highest educated men were in fact statistically significantly less often inclined to stop smoking within 6 months than their lowest educated peers, independent of the components of the TPB, as shown by the negative and statistically significant direct effect of education on intention to quit within 6 months (table 6).

Mediation analyses also revealed that the TPB statistically significantly mediated differences in the intention to quit smoking within 1 or 6 months between the lowest educated Chinese men and the lower and highest educated groups, as shown by the statistically significant total indirect effect (figure 2 and table 6). The most influential component of the TPB was subjective norms. The higher the educational level the stronger the subjective social norm towards smoking cessation, which lead to stronger intentions to quit. Furthermore, the highest educated group of smokers was also significantly

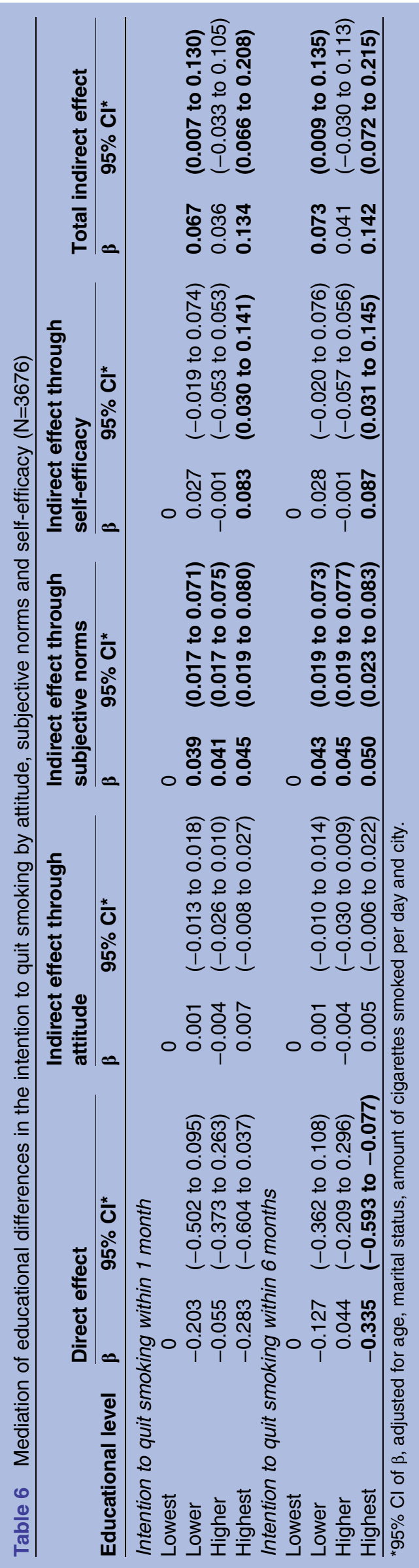


Figure 2 Mediation pathways

(indirect effects only) between

educational level and the

intention to stop smoking within 1

or 6 months.

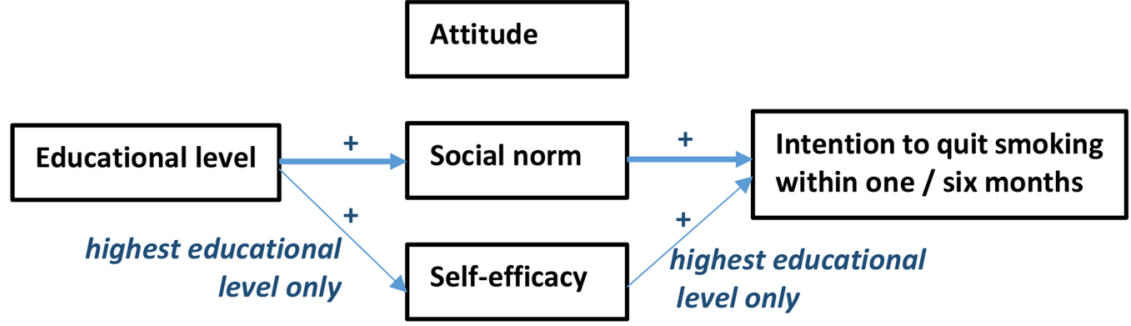

Attitude

level only more often inclined to quit smoking than their lowest educated counterparts, due to their higher perceived ability to succeed in doing so (table 6).

Mediation analyses also showed that the direct association between education and the intention to quit smoking was larger than the indirect pathway involving the elements of the TPB (table 6). This means that there are other (more) influential determinants that can explain educational differences in the intention to quit smoking among Chinese men.

\section{DISCUSSION}

A less negative personal attitude, a stronger perceived subjective norm towards smoking cessation and a higher perceived self-efficacy to quit smoking were associated with the intention to quit smoking among Chinese male smokers. No educational disparities in the intention to quit smoking were initially observed among male Chinese smokers. However, an educational gradient in subjective norm was associated with educational differences in the intention to quit smoking within 1 and 6 months; the higher the educational level, the higher the perceived subjective norms towards smoking cessation and the related intention to quit smoking. The highest educated smokers were also more likely to intend to quit smoking than their peers, because of their higher perceived self-efficacy.

We observed no educational differences in the intention to quit smoking among Chinese male smokers. This finding was in line with the findings from a Dutch study. ${ }^{12}$ Still, earlier studies reported that Chinese men who had no formal education or were illiterate smoked for more years than those who had a college degree or higher education. ${ }^{22}$ This discrepancy may be explained by our findings that, although all educational groups have the same intention to quit smoking, the self-efficacy to do so is higher among the higher educated. As a result they are more successful in quitting smoking and reducing their smoking duration than their lower educated peers. Still, it may also be argued that the existing socioeconomic disparities in smoking prevalence in China $^{45}$ are not merely the result of disparities in smoking cessation, but may well be the consequence of differences in the uptake of smoking, as has been reported in the USA. ${ }^{11}$ This argument is in line with Fu's report about sociocultural factors favouring smoking initiation among young people being one of the major reasons for the lack of effectiveness of current tobacco control measures in China. ${ }^{20}$

All three elements of the TPB, that is attitude, perceived social norms and perceived self-efficacy, were highly correlated with the intention to quit smoking. The TPB also mediated the association between educational level and the intention to quit smoking. This is in line with the conclusion of a large meta-analysis that concluded that attitude, subjective norms and selfefficacy together accounted for only $44.3 \%$ of the variance in intention. ${ }^{22}$ Our results suggest that additional factors may play a role in determining educational differences in the intention to quit smoking. These might be the more unintentional influences that shape behaviour, as put forward by critics of the TPB. ${ }^{18}$ Further research might want to look into such additional factors, which might even be more amenable to change by interventions and programmes.

China urgently needs to develop and implement effective smoking interventions. Smoking prevalence is consistently high and is rising among the younger men and females. In addition, smoking-related mortality is as high as 1.2 million per year, and is expected to rise to 2 million by $2025 .^{23}$ The application of the TPB presented in this paper has provided information that is extremely useful to understand smoking cessation behaviours in China, and hence may provide valuable input for the design and development of effective interventions. Based on our results, we conclude that, in order to increase the intention to quit smoking among Chinese male smokers, interventions that create a more positive attitude towards smoking cessation, increase the social pressure to quit smoking through significant others, and improve smoker's self-efficacy may be effective.

This paper shows that educational differences in the intentions to quit smoking in China may originate from existing educational differences in the perceived social norms towards smoking cessation. Although subjective norms are generally considered the least important component of the TPB in predicting intention, ${ }^{22}$ we found that the educational gradient in subjective norms was the component of the TPB that particularly affected the educational gradient in the intention to quit smoking among Chinese men. In order to prevent future educational disparities in smoking cessation to rise, efforts to create a more stimulating social environment and stricter social norms towards smoking cessation among lower educated Chinese men are urgently needed. These 
prevention programmes might benefit from a social network approach that enables the identification of potential targets for altering social norms. ${ }^{24}$

Author affiliations

${ }^{1}$ Key Laboratory of Public Health Safety, Ministry of Education, School of Public Health, Fudan University, Shanghai, China

${ }^{2}$ Center of Disease Control, Pudong District, Shanghai, China

${ }^{3}$ Mudanjiang Medical University, Mudanjiang, Heilongjiang Province, China

${ }^{4}$ Nanning Medical University, Guangxi Zhuang Autonomous Region, China

Contributors MD planned the paper, developed the plan of analyses and wrote the major part of the manuscript. XH performed all analyses and helped writing the Methods section of this paper. $\mathrm{XH}$ and WF collected the data in Shanghai, YY in Mudanjiang and the Nanning data was collected by HL. PZ was the principal investigator who designed and led this project. She gave helpful suggestions for writing this paper. All authors read and approved the final version of the manuscript.

Funding This study was supported by the National Nature Science Foundation of China, fund number 71203033.

Competing interests None declared.

Patient consent Obtained.

Ethics approval The study was granted approval by the Ethics Committee of the School of Public Health, Fudan University.

Provenance and peer review Not commissioned; externally peer reviewed.

Data sharing statement Extra data can be accessed via the Dryad data repository at http://datadryad.org/ with the doi:10.5061/dryad.324f2.

Open Access This is an Open Access article distributed in accordance with the Creative Commons Attribution Non Commercial (CC BY-NC 4.0) license, which permits others to distribute, remix, adapt, build upon this work noncommercially, and license their derivative works on different terms, provided the original work is properly cited and the use is non-commercial. See: http:// creativecommons.org/licenses/by-nc/4.0/

\section{REFERENCES}

1. Kulik MC, Hoffmann R, Judge K, et al. Smoking and the potential for reduction of inequalities in mortality in Europe. Eur $\mathrm{J}$ Epidemiol 2013;28:959-71.

2. Jarvis MJ, Wardle J. Social patterning of health behaviours: the case of cigarette smoking. In: Marmot M, Wilkinson RG, eds. Social determinants of health. 2nd edn. Oxford: Oxford University Press, 2006:224-37.

3. Jha P, Peto R, Zatonski W, et al. Social inequalities in male mortality, and in male mortality from smoking: indirect estimation from national death rates in England and Wales, Poland, and North America. Lancet 2006;368:367-70.
4. Palipudi KM, Gupta PC, Sinha DN, et al., GATS Collaborative Group. Social determinants of health and tobacco use in thirteen low and middle income countries: evidence from Global Adult Tobacco Survey. PLOS ONE 2012;7:e33466.

5. Hosseinpoor AR, Parker LA, Tursan d'Espaignet E, et al. Socioeconomic inequality in smoking in low-income and middle-income countries: results from the World Health Survey. PLOS ONE 2012;7:e42843.

6. Yang G, Hu A. Tobacco control and the future of China: the joint assessment report of tobacco control situation in China [newspaper article]. Beijing: Economic Daily Press, 2011.

7. ITC Project and Office of Tobacco Control, China CDC. ITC China Project Report. Findings from the Wave 1 to 3 Surveys (2006-2009). Beijing: China Modern Economic Publishing House, 2012.

8. $\mathrm{Ng} \mathrm{M}$, Freeman MK, Fleming TD, et al. Smoking prevalence and cigarette consumption in 187 countries, 1980-2012. JAMA 2014;311:183-92.

9. Droomers M, Schrijvers CT, Casswell S, et al. Father's occupational group and daily smoking during adolescence: patterns and predictors. Am J Public Health 2005;95:681-8.

10. Legley S, Janssen E, Beck F, et al. Social gradient in initiation and transition to daily use of tobacco and cannabis during adolescence: a retrospective cohort study. J Addict Med 2011;106:1520-31.

11. Maralani V. Educational inequalities in smoking: the role of initiation versus quitting. Soc Sci Med 2013;84:129-37.

12. Droomers M, Schrijvers CT, Mackenbach JP. Educational differences in the intention to stop smoking: explanations based on the Theory of Planned Behaviour. Eur J Public Health 2004;14:194-8.

13. Legleye $\mathrm{S}$, Khlat M, Beck $\mathrm{F}$, et al. Widening inequalities in smoking initiation and cessation patterns: a cohort and gender analysis in France. Drug Alcohol Depen 2011;117:233-41.

14. Schaap MM, Kunst AE, Leinsalu M, et al. Effect of nationwide tobacco control policies on smoking cessation in high and low educated groups in 18 European countries. Tob Control 2008;17:248-55.

15. Ajzen I. The theory of planned behaviour. Organ Behav Human Decision Proces 1991:50:179-211.

16. Sheeran P, Gollwitzer PM, Bargh JA. Nonconscious processes and health. Health Psychol 2013; 32:460-73.

17. Ajzen I. The theory of planned behaviour: reactions and reflections. Psychol Health 2011;26:1113-27.

18. Sniehotta FF, Presseau J, Araújo-Soares V. Time to retire the theory of planned behaviour. Health Psychol Rev 2014:8:1-7.

19. Department of Population and Employment Statistics National Bureau of Statistics of China. China population \& employment statistics yearbook 2012. Beijing: China Statistics Press, 2013.

20. Fu W. Smoking rationalizing beliefs among the Chinese male smokers [MSc dissertation in Chinese]. Shanghai: Fudan University, School of Public Health, 2014.

21. Hayes AF. Beyond Baron and Kenny: statistical mediation analysis in the New Millennium. Commu Monogr 2009;76:408-20.

22. Guo H, Sa Z. Socioeconomic differentials in smoking duration among adult male smokers in China: result from the 2006 China Health and Nutrition Survey. PLOS ONE 2015;10:e0117354.

23. Zhang J, Ou JX, Bai CX. Tobacco smoking in China: prevalence, disease burden, challenges and future strategies. Respirology 2011;16:1165-72.

24. Gest SD, Osgood DW, Feinberg M, et al. Strengthening prevention program theories and evaluations: contributions from social network analysis. Prev Sci 2011;12:349-60. 